\title{
Construction of occluded recombinant baculoviruses containing the full-length cry1Ab and cry1Ac genes from Bacillus thuringiensis
}

B.M. Ribeiro and N.E. Crook ${ }^{\dagger}$
Horticulture Research International, Littlehampton, West Sussex, UK

\section{Correspondence}

B.M. Ribeiro

Departamento de Biologia Celular

Universidade de Brasília

70191-970 Brasília, DF

Brasil

Fax: 55 (061) 347-6533

E-mail:

bergmann@guarany.cpd.unb.br

Research supported by CNPq and MAFF (United Kingdom).

tDeceased

Received December 12, 1997

Accepted March 26, 1998

\section{Abstract}

The administration of baculoviruses to insects for bioassay purposes is carried out, in most cases, by contamination of food surfaces with a known amount of occlusion bodies (OBs). Since per os infection is the natural route of infection, occluded recombinant viruses containing crystal protein genes (crylA $b$ and crylAc) from Bacillus thuringiensis were constructed for comparison with the baculovirus prototype Autographa californica nucleopolyhedrovirus (AcNPV). The transfer vector $\mathrm{pAcUW} 2 \mathrm{~B}$ was used for construction of occluded recombinant viruses. The transfer vector containing the crystal protein genes was cotransfected with linearized DNA from a non-occluded recombinant virus. The isolation of recombinant viruses was greatly facilitated by the reduction of background "wild type" virus and the increased proportion of recombinant viruses. Since the recombinant viruses containing full-length and truncated forms of the crystal protein genes did not seem to improve the pathogenicity of the recombinant viruses when compared with the wild type AcNPV, and in order to compare expression levels of the full-length crystal proteins produced by nonoccluded and occluded recombinant viruses the full-length crylA $\mathrm{b}$ and $c r y l A c$ genes were chosen for construction of occluded recombinant viruses. The recombinant viruses containing full-length and truncated forms of the crystal protein genes did not seem to improve its pathogenicity but the size of the larvae infected with the recombinant viruses was significantly smaller than that of larvae infected with the wild type virus.

\section{Introduction}

Baculoviruses are a potential source of biopesticides for the control of insect pests. Recombinant baculoviruses which express toxins have been constructed and shown to have an improved insecticidal activity (1-5).
Key words

- Baculovirus

- AcNPV

- Bacillus thuringiensis

cry $1 A$

- Pieris brassicae
- Heliothis virescens 
tal proteins are potent insecticides and exibit a very high degree of insect specificity. They are produced in large amounts during sporulation of B. thuringiensis and appear as large crystals. When they are ingested by a susceptible insect the crystal proteins are dissolved and proteolytically cleaved to a smaller active polypeptide in the alkaline environment of the insect midgut. The activated toxin has a cytolytic effect on the midgut cells. The insect stops feeding and eventually dies. In a previous study, we introduced the full-length and truncated forms of the $c r y l A b$ gene and the full-length crylAc gene of Bacillus thuringiensis into the genome of the baculovirus Autographa californica nucleopolyhedrovirus (AcNPV) under the control of the polyhedrin promoter (6). These recombinant viruses expressed the toxins and were nonoccluded. In order to bioassay the virus we had to inject the budded form of the virus into the hemocele of the insect. In the present paper we report the introduction of the full-length $c r y l A b$ and $c r y l A c$ genes from B. thuringiensis into the genome of AcNPV under the control of the p10 promoter. The recombinant viruses constructed had the polyhedrin gene and consequently produced the occluded form of the virus. Since per os infection is the natural route of infection for baculoviruses, the occluded recombinant viruses containing the crystal protein genes were used for comparison with the baculovirus prototype AcNPV. The expression of crystal proteins in insect cells and insect larvae, and the pathogenicity of recombinant viruses towards a susceptible insect were analyzed.

\section{Material and Methods}

\section{Restriction enzymes and reagents}

All restriction enzymes used in the present study were obtained from GibcoBRL (Gaithersburg, MD). The reagents were obtained from Gibco-BRL and Sigma Chem- ical Company (St. Louis, MO).

\section{Virus, cells and insects}

AcNPV strain C6 (11) and AcRP5ßgal virus (Ribeiro BM, unpublished results) were used to infect Spodoptera frugiperda(IPLBSF-21) cells grown in TC100 medium supplemented with $5 \%$ fetal calf serum. Virus was titrated by the plaque assay (12).

Heliothis virescens and Pieris brassicae were reared under hygienic conditions using artificial diets $(13,14)$. H. virescens was used for the bioassays with polyhedra since this insect is susceptible to the AcNPV virus. $P$. brassicae was used to test the Cry protein activity since this insect is not susceptible to AcNPV but is highly sensitive to the Cry1A toxins.

\section{Construction of a transfer vector containing the full-length genes $c r y 1 A b$ and $c r y 1 A c$}

The strategy for cloning the full-length genes crylAb and crylAc is shown in Figure 1. Ten micrograms of the plasmids pUCBtm and pUCBt73 (6) was digested with BamHI and separated on $1 \%$ agarose gel. The bands containing the genes were recovered from the gel (15) and suspended in a small volume of TE buffer. The transfer vector pAcUW2B was digested with $B g / I I$, dephosphorylated and ligated to the $c r y l A b$ and $c r y l A c$ genes. The ligation mixture was transformed into $E$. coli DH5 $\alpha$ cells, and colonies were screened for the presence of the crystal protein genes. The recombinant transfer vectors $\mathrm{pAcOBtm}$ and pAcOBt73 respectively containing the $c r y 1 A b$ and $c r y 1 A c$ genes were then isolated from a large-scale plasmid DNA preparation and stored at $-20^{\circ} \mathrm{C}$.

\section{Co-transfection of Spodoptera frugiperda cells and isolation of recombinant viruses}

DNA of the recombinant transfer vectors pAcOBtm and pAcOBt73 was co-transfected 
with linearized DNA from the non-occluded AcRP5ßgal virus. The non-occluded AcRP5 Bgal virus was constructed by introducing the Escherichia coli ß-galactosidase gene into the AcNPV genome in place of the polyhedrin gene (Ribeiro BM, unpublished results). In this study, DNA from AcRP5ßgal was digested with Bsu36I which hydrolyzes the viral DNA at only one location (5'-end of the $\beta$-galactosidase gene). Linear viral DNA (500 ng) was co-transfected with 1-2 $\mu \mathrm{g}$ of transfer vector DNA into $S$. frugiperda cells using the liposome-mediated transfection method (16). After $48 \mathrm{~h}$ the whole medium from transfected cells was mixed with $1 \mathrm{x}$ $10^{6}$ S. frugiperda cells and seeded onto a 96well plate. The plate was incubated at $27^{\circ} \mathrm{C}$ for 5 days and the wells were screened for the presence of polyhedra by light microscopy and by dot blot hybridization (data not shown). Medium from strongly positive wells was mixed and passed twice in 96-well plates. Medium from single positive wells from the later passage was then used to infect $H$. virescens larvae. After insect death, polyhedra were purified and the DNA isolated. The purity of the recombinant viruses was checked by restriction endonuclease digestion of viral DNA (Figure 2).

\section{Expression of crystal proteins in insect larvae by the occluded recombinant viruses}

Insect cells were infected with AcOBtm and AcOBt73 (10 pfu/cell) and 3rd-instar insect larvae were infected by spreading 100 to 1000 occlusion bodies on small cabbage leaf discs. After the liquid dried, the leaf discs were given to individual larvae and incubated at $27^{\circ} \mathrm{C}$ overnight. Insects which consumed all the leaf disc were transferred to replica dishes containing a plug of artificial diet and incubated at $27^{\circ} \mathrm{C}$ until they succumbed to the virus. The expression of the crystal proteins in insect larvae was analyzed by SDS-PAGE (Figure 3) and immunoblotting (data not shown).

\section{Bioassay of occluded recombinat viruses}

The droplet feeding method (17) was used for the bioassay of the occluded recombinant viruses. The amount of OBs ingested by the larvae of $H$. virescens was calculated indirectly by the determination of the ingested volume by fluorescence spectroscopy (18). Mean lethal concentrations $\left(\mathrm{LC}_{50}\right)$ were estimated by probit analysis. Homogenates from insects $(H$. virescens) infected with AcOBtm and AcOBt73 were serially diluted and incorporated into the artificial diet. Twenty newly hatched $P$. brassicae larvae were incubated with the diet for 5 days and two parameters of insect mortality, mean

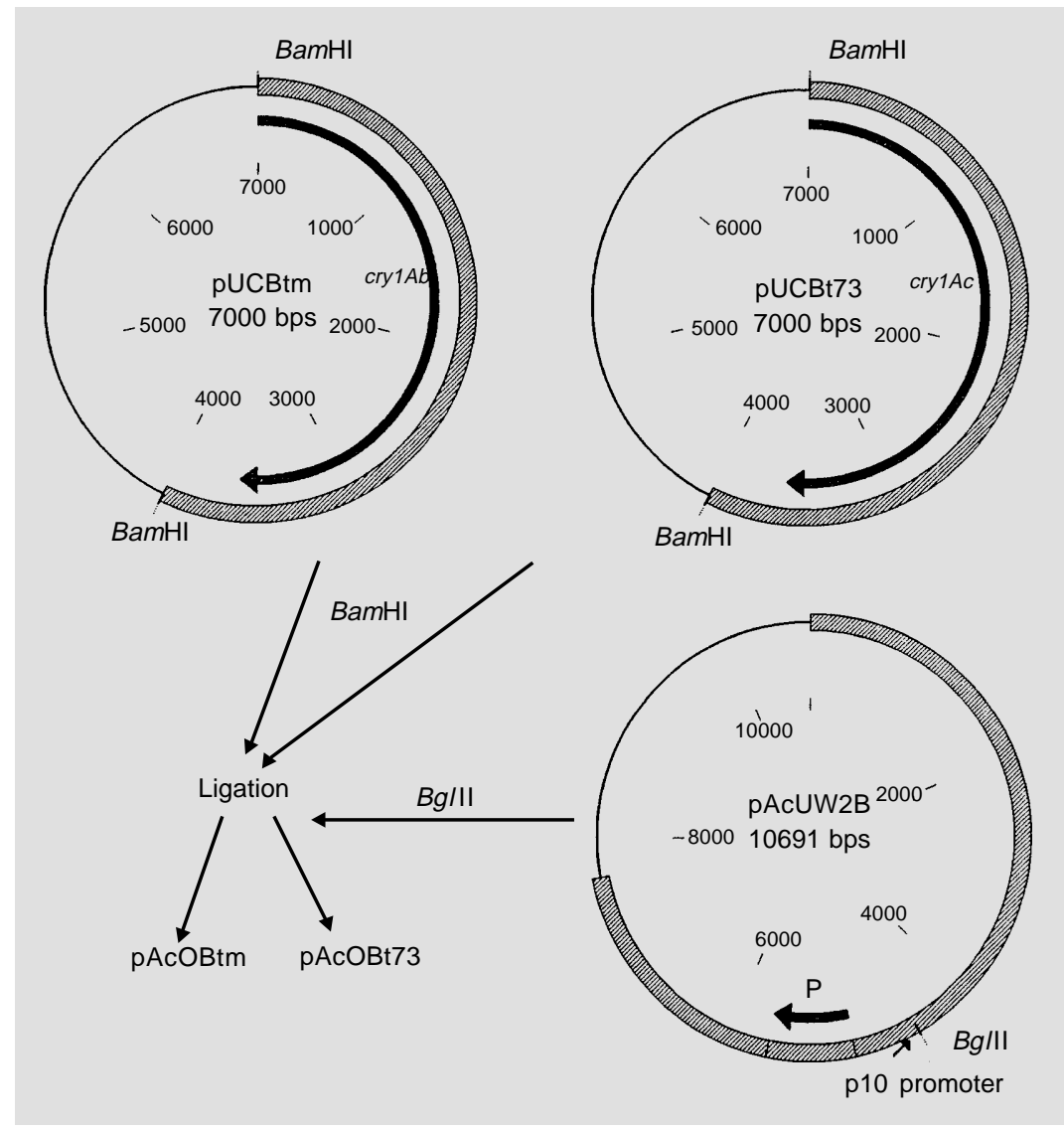

Figure 1 - Construction of transfer vectors pAcOBtm and pAcOBt73. Plasmids pUCBtm and pUCBt73, containing the $c r y 1 A b$ and $c r y 1 A c$ genes, respectively, were digested with $B a m H I$ and the fragments containing the genes were cloned into plasmid pAcUW2B previously digested with Bg/ll. The large arrows in pUCBtm, pUCBt73 and pAcUW2B represent the open reading frames of the $c r y 1 A b$, cry $1 A c$ and polyhedrin $(P)$ genes, respectively. The small arrow in pAcUW2B represents the $\mathrm{p} 10$ promoter. 
Figure 2 - Analysis of the DNA from the recombinant viruses. Electrophoresis on $1 \%$ agarose gel of an EcoRI digest of DNA from the occluded recombinant viruses $\mathrm{AcOBtm}$ and $\mathrm{AcOB}$ 73 Arrowheads indicate the extra DNA fragment bands corresponding to the insertion of the toxin gene constructs into the AcNPV genome. lethal dose $\left(\mathrm{LD}_{50}\right)$ and lethal half-time $\left(\mathrm{LT}_{50}\right)$, were estimated by probit analysis (Table 1). For the measurement of $\mathrm{LD}_{50}$, serially diluted OBs from the recombinant and wild type virus were given to the insects (25-50 newly hatched larvae). Mortality was recorded 10 days post-infection. For the measurement of $\mathrm{LT}_{50}, 300 \mathrm{OBs} / \mathrm{nl}$ were used, mortality was recorded at 8-h intervals from day 4 to day 10, and the bioassays repeated 4 times. Calculated mean values and their stan-

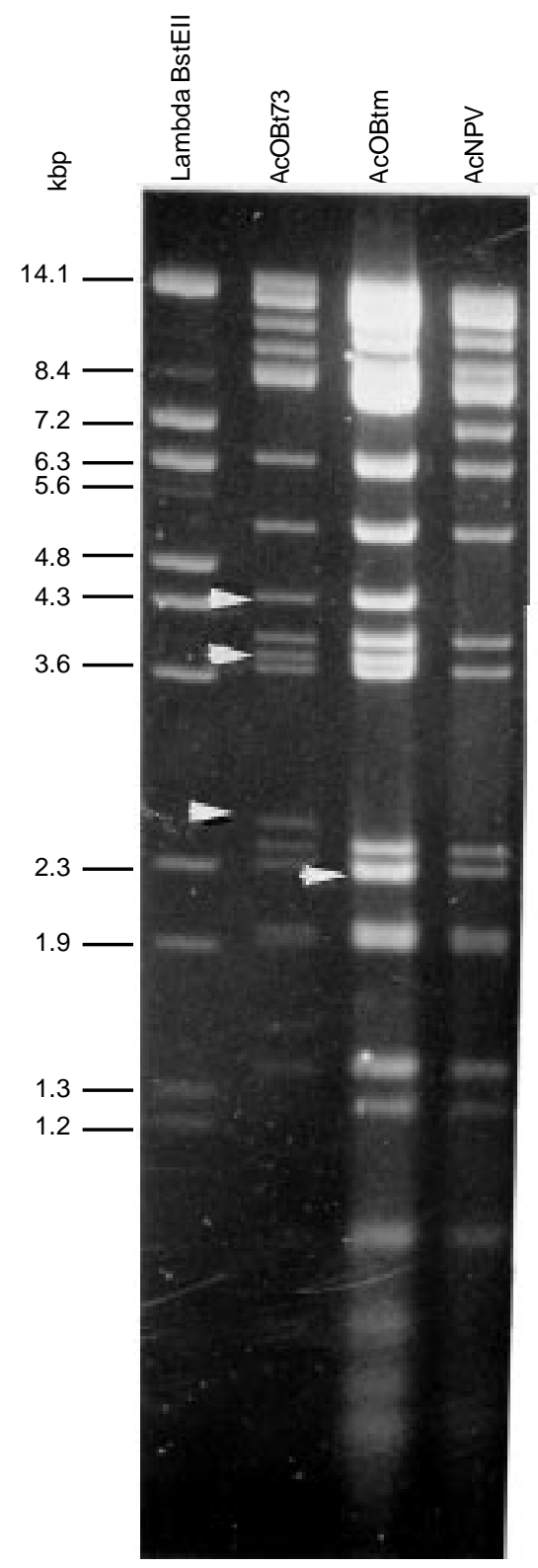

dard error of the mean were analyzed by ANOVA.

\section{Results}

\section{Construction of a transfer vector containing the full-length genes cry1Aband cry1Ac}

Figure 1 shows the strategy for the cloning of the full-length $c r y l A b$ and $c r y l A c$ genes. The $c r y l A b$ and $c r y l A c$ genes from $B$. thuringiensis were removed from the plasmids pUCBtm and pUCBt73 (6) and cloned into the transfer vector $\mathrm{pAcUW} 2 \mathrm{~B}$. The resulting plasmids pAcOBtm and pAcOBt73 were used for the construction of the recombinant viruses.

\section{Co-transfection of Spodoptera frugiperda cells and isolation of recombinant viruses}

The plasmids pAcOBtm and pAcOBt73 were used together with linearized DNA from the non-occluded AcRP5ßgal virus for the co-transfection of IPLB-SF-21 cells. After $48 \mathrm{~h}$, the cell supernatant was collected and used for the isolation of the recombinant viruses by a combination of the end-point dilution method and Southern-blot (16). The purified recombinant virus was amplified in IPLB-SF-21 cells and the DNA extracted (16). The DNA was subjected to restriction enzyme analysis and compared to the DNA of the wild type virus (Figure 2). The purity of the recombinant virus was confirmed by the appearance of new bands of the expected sizes for each gene (Figure 2, arrowheads), and by Southern-blot (data not shown).

\section{Expression of crystal proteins in insect larvae by the occluded recombinant viruses}

The full-length crystal proteins produced by the occluded recombinant viruses AcOBtm and AcOBt73 were similar in size (as determined by SDS-PAGE) to the authentic crystal proteins expressed by the $B$. 
thuringiensis(Figure 3). They also proved to be immunologically similar since they reacted with antiserum raised against authentic Cry1 Ac crystal protein (data not shown).

The levels of expression of the crylA $b$ and $c r y l A c$ proteins in insect cells infected with the occluded viruses AcOBtm and AcOBt 73 were shown to be at least $1 / 5$ of the expression of the same proteins in insects infected with the non-occluded viruses AcBtm and AcBt73 (see Tables 1 and 2 in Ribeiro and Crook (6)).

\section{Biological activity of the crystal proteins expressed by the occluded recombinant viruses}

Crystal protein genes expressed in insect larvae were shown to be biologically active against $P$. brassicae. Insect suspensions from insects infected with AcOBtm and AcOBt73 were serially diluted and incorporated into the artificial diet. Twenty newly hatched $P$. brassicae larvae were incubated with the diet for 5 days and insect mortality was analyzed by probit analysis (Table 1 ). The proteins expressed by the two recombinant viruses showed the same level of toxicity towards $P$. brassicae larvae.

\section{Bioassay of occluded recombinat viruses}

The mean volume ingested by larvae of $H$. virescens by the droplet feeding method was $14.48 \mathrm{nl}$, with a standard error of 6.88 . The results of the $\mathrm{LD}_{50}$ bioassays using the susceptible $H$. virescens (Table 2) showed that the $\mathrm{LD}_{50}$ of AcOBtm and of AcOBt73 were at least 2 times greater than that of the wild type virus. The $\mathrm{LT}_{50}$ bioassays (Tables 3 and 4) showed that the values for AcOBtm and $\mathrm{AcOBt} 73$ were significantly higher than the values for AcNPV.

\section{Discussion}

Occluded recombinant viruses contain-

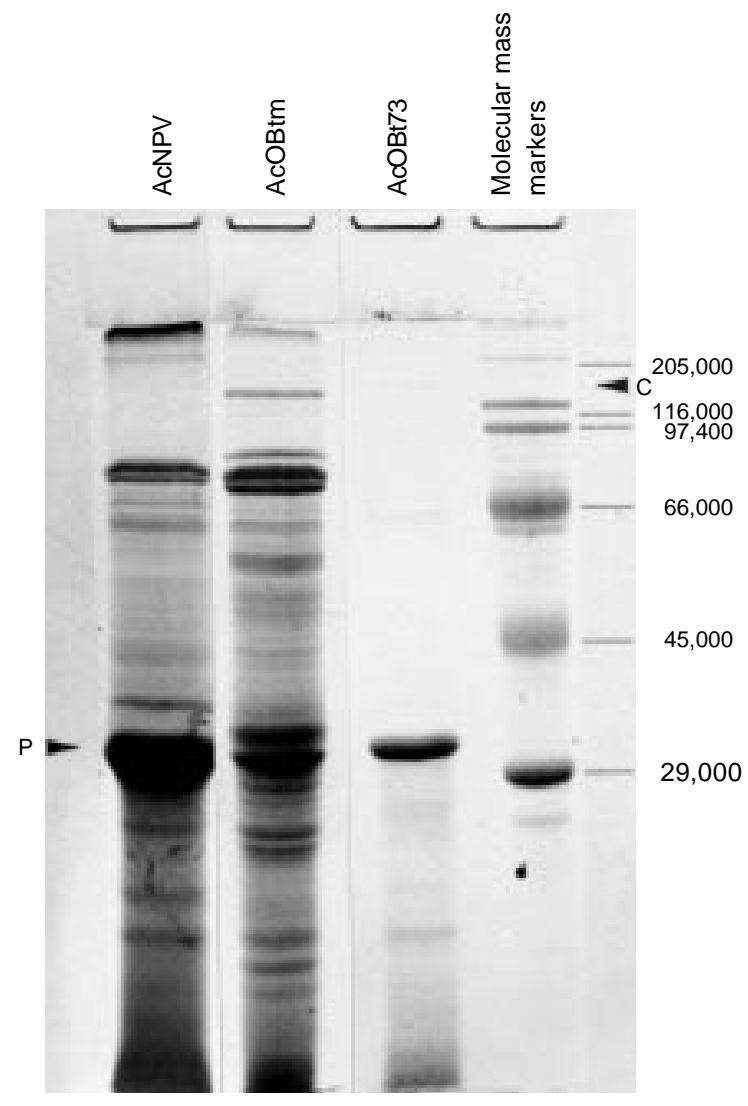

Figure 3 - Expression of crystal proteins in insect larvae. Polyacrylamide gel electrophoresis (PAGE) of extracts prepared from insects infected with the occluded recombinant viruses containing the cry $1 A b$ and cry $1 A c$ genes. The arrowheads show the position of the crystal proteins (C) and polyhe$\operatorname{drin}(\mathrm{P})$.
Table $1-\mathrm{LC}_{50}$ values for the crystal proteins produced by the occluded viruses containing the full-length $c r y 1 A b$ and $c r y 1 A c$ genes.

C.L. = Confidence limits, CHI-SQ = residual chi-square, d.f. $=$ degrees of freedom, $\mathrm{SEM}=$ standard error of the mean. The residual chi-squares are not significant.

\begin{tabular}{lcccccc}
\hline Virus & CHI-SQ & d.f. & slope & $\begin{array}{c}\text { SEM } \\
(\text { slope })\end{array}$ & $\begin{array}{c}\text { LC50 } \\
(\mu \mathrm{g} \text { insect/g diet } \\
\text { suspension })\end{array}$ & C.L. \\
\hline AcOBtm & 2.12 & 2 & 1.2 & 0.2 & 0.08 & $0.04 \div 0.13$ \\
AcOBt73 & 4.19 & 2 & 1.6 & 0.3 & 0.05 & $0.03 \div 0.08$
\end{tabular}

Table $2-\mathrm{LD}_{50}$ values for the occluded recombinant viruses AcOBtm and AcOBt73 using $H$. virescens.

C.L. = Confidence limits, CHI-SQ $=$ residual chi-square, d.f. $=$ degrees of freedom, $\mathrm{SEM}=$ standard error of the mean. The residual chi-squares are not significant.

\begin{tabular}{lcccccc}
\hline Virus & CHI-SQ & d.f. & slope & SEM (slope) & LD $_{50}(\mathrm{OBs})$ & C.L. \\
\hline AcNPV & 0.81 & 2 & 1.8 & 0.3 & 168 & $114 \div 253$ \\
AcOBt73 & 1.76 & 2 & 1.8 & 0.4 & 453 & $305 \div 820$ \\
AcOBtm & 10.0 & 2 & 0.7 & 0.14 & 380 & $155 \div 1258$
\end{tabular}




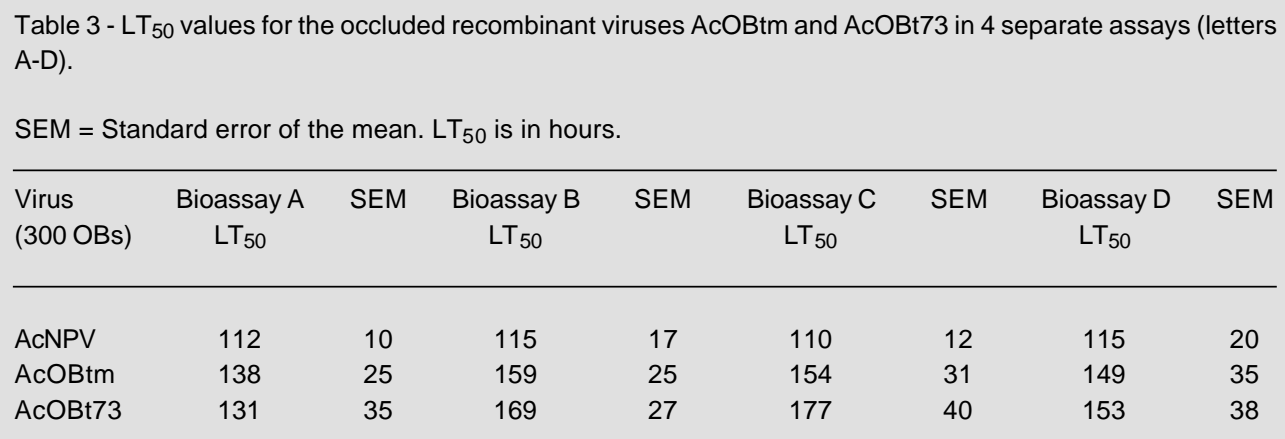

Table $4-\mathrm{LT}_{50}$ analysis of the 4 bioassays for the occluded AcOBtm and $\mathrm{AcOBt73}$ recombinant viruses.

$\mathrm{SEM}=$ Standard error of the mean.

\begin{tabular}{lcc}
\hline Virus & $\mathrm{LT}_{50}$ & SEM \\
\hline AcNPV & 112 & 2 \\
AcOBtm & 148 & 5 \\
AcOBt73 & 158 & 6
\end{tabular}

ing the full-length genes $c r y l A b$ and $c r y l A c$ from $B$. thuringiensis were constructed. The crystal proteins produced in insect larvae by the recombinant occluded viruses were shown to be immunologically similar to the authentic crystal proteins produced in $B$. thuringiensis. Furthermore, they proved to be biologically active against $P$. brassicae. We have shown previously (6) that the expression of full-length and truncated forms of the $c r y l A b$ gene and the full-length $c r y l A c$ gene in insect cells and insects by recombinant non-occluded baculoviruses produced proteins biologically and immunologically similar to their native counterparts. Martens et al. $(8,9)$ also reported the expression of different forms of the Cry1Ab crystal protein from B. thuringiensis in insect cells, showing that the expressed proteins were biologically active. Full-length ( $72 \mathrm{kDa})$ and truncated $(61 \mathrm{kDa})$ Cry11Aa proteins from B. thuringiensis were also expressed in insect cells by recombinant baculoviruses. These proteins formed cuboidal crystals and only the full-length protein was shown to be toxic to insects (10). The crystal protein from $B$. thuringiensis subsp. kurstaki HD-73 was expressed in insect cells by a recombinant baculovirus and also showed biological activity (7).

Despite the fact that the crystal proteins were expressed at high levels in insects, the pathogenicity of the recombinant occluded viruses was not improved by the presence of either crystal protein. The $\mathrm{LD}_{50}$ values for the occluded recombinant viruses AcOBtm and $\mathrm{AcOBt} 73$ were about 2 to 3 times higher than for the wild type virus. This result is in accordance with the data obtained by Merryweather et al. (7). They also obtained an $\mathrm{LD}_{50}$ about 2 times higher for an occluded recombinant baculovirus expressing the HD73 crystal protein. The levels of expression of the Cry $1 \mathrm{Ab}$ and Cry $1 \mathrm{Ac}$ proteins in insect cells infected with the occluded viruses AcOBtm and AcOBt73 were shown to be at least $1 / 5$ of the expression of the same proteins in insects infected with the non-occluded viruses AcBtm and AcBt73 ((6), Tables 1 and 2). This lower expression could be due to the simultaneous expression of the polyhedrin gene, since they might compete for the same resources inside the cell. The failure to improve the insecticidal activity is not due to the production of the protein inside the cell. Martens et al. (9) showed that the production and or secretion of the Cry $1 \mathrm{Ab}$ protoxin or the mature toxin by the recombinant baculoviruses did not increase insecticidal activity. They postulated that the 
protoxins produced are inactive and not likely to be activated in vivo, secretion of the protoxins is poor and production of the mature toxins results in cytotoxicity. Although the expression of crystal proteins from $B$. thuringiensis in insect cells by recombinant baculovirus does not increase pathogenicity, as measured by the bioassay results, we noted that the size of the larvae infected with the recombinant viruses was significantly smaller than that of larvae infected with the wild type virus. This is probably due to contamination of the OBs with crystal proteins. The expression of $B$. thuringiensis crystal pro- teins in insect cells could be useful for the study on the mode of action of such proteins since they assemble in crystals similar to those found in bacteria and have been shown to be biologically active $(6,10)$.

\section{Acknowledgments}

We thank Dr. Robert D. Possee for providing the AcNPV wild-type virus, Spodoptera frugiperda cells and transfer vector pAcUW2B, Paul Jarret for the crylAb gene, Dr. Doreen Winstanley for the crylAc gene, and John Fenlon for statistical advice.

\section{References}

1. Lu A, Seshagiri S \& Miller LK (1996). Signal sequence and promoter effects on the efficacy of toxin-expressing baculoviruses as biopesticides. Biological Control, 3: 320-332.

2. Stewart LMD, Hirst $M$, Ferber $M L$, Merryweather AT, Cayley PJ \& Possee RD (1991). Construction of an improved baculovirus insecticide containing an insect-specific toxin gene. Nature, 352: 8588.

3. McCutchen BF, Choudary PV, Crenshaw R, Maddox D, Kamita SG, Palekar N, Volrath S, Fowler E, Hammock BD \& Maeda S (1996). Development of a recombinant baculovirus expressing an insect-selective neurotoxin: potential for pest control. Bio/Technology, 9: 848-852.

4. Tomalski MD \& Miller LK (1991). Insect paralysis by baculovirus-mediated expression of a mite neurotoxin gene. Nature, 352: 82-85.

5. Tomalski MD \& Miller LK (1992). Expression of a paralytic neurotoxin gene to improve insect baculoviruses as biopesticides. Bio/Technology, 10: 545-549.

6. Ribeiro BM \& Crook NE (1993). Expression of full-length and truncated forms of crystal protein genes from Bacillus thuringiensis subsp. kurstaki in a baculovirus and pathogenicity of the recombinant viruses. Journal of Invertebrate Patholo- gy, 62: 121-130.

7. Merryweather AT, Weyer U, Harris MP, Hirst M, Booth T \& Possee RD (1990). Construction of genetically engineered baculovirus insecticides containing the Bacillus thuringiensis subsp. kurstaki HD73 delta endotoxin. Journal of General Virology, 71: 1535-1544.

8. Martens JWM, Honee G, Zuidema D, Van Lent JWM, Visser B \& Vlak JM (1990). Insecticidal activity of a bacterial crystal protein expressed by a recombinant baculovirus in insect cells. Applied and Environmental Microbiology, 56: 27642770.

9. Martens JW, Knoester M, Weijts F, Groffen SJ, Hu Z, Bosh D \& Vlak JM (1995). Characterization of baculovirus insecticides expressing tailored Bacillus thuringiensis $\mathrm{CrylA}(\mathrm{b})$ crystal proteins. Journal of Invertebrate Pathology, 66: 249-257.

10. Pang $Y$, Frutos $R$ \& Federici BA (1992). Synthesis and toxicity of full-length and truncated bacterial Cry11Aa mosquitocidal proteins expressed in lepidopteran cells using a baculovirus vector. Journal of General Virology, 73: 89-101.

11. Possee RD, Sun T-P, Howard SC, Ayres MD, Hill-Perkins M \& Gearing K (1991). Nucleotide sequence of the Autographa californica nuclear polyhedrosis virus 9.4 kbp EcoRI-I and -R (polyhedrin gene) region. Virology, 185: 229-241.

12. Brown M \& Faulkner P (1977). A plaque assay for nuclear polyhedrosis viruses using a solid overlay. Journal of General Virology, 36: 361-364.

13. David WAL \& Gardiner BOC (1965). Rearing Pieris brassicae L. larvae on a semisynthetic diet. Nature, 207: 882-883.

14. Guennelon G, Audemard H, Fremond JC \& El Idrissi Ammari MA (1981). Progrès realisés dans l'élevage permanent du carpocapse (Laspeyresia pomonella) sur milieu artificiel. Agronomie, 1: 59-64.

15. Sambrook J, Fritsh EF \& Maniatis T (1989). Molecular Cloning: A Laboratory Manual. 2nd edn. Cold Spring Harbor Laboratory Press, New York.

16. O'Reilly DR, Miller LK \& Luckow VA (1992). Baculovirus Expression Vectors. A Laboratory Manual. W.H. Freeman and Company, New York.

17. Hughes PR \& Wood HA (1981). A synchronous peroral technique for the bioassay of insect viruses. Journal of Invertebrate Pathology, 37: 154-159.

18. van Beek NAM \& Hughes PR (1986). Determination by fluorescence spectroscopy of the volume ingested by neonate lepidopterous larvae. Journal of Invertebrate Pathology, 48: 249-251. 